\title{
The Emergence of Solar Photovoltaic Technology in Indonesia: Winners and Losers
}

\author{
Arriyadhul Qolbi ${ }^{1, *}$ \\ ${ }^{1}$ Energy Systems, The University of Melbourne, Australia
}

\begin{abstract}
As the solar energy technology has been more competitive recently, it is common to see studies which examined how solar photovoltaic can technically emerge in the energy system in Indonesia. However, less research is conducted to study how the emergence of solar photovoltaic might impact different stakeholders in the electricity market in Indonesia. The increase of solar photovoltaic deployment will create winners and losers among the main stakeholders which are: the consumers, the national electricity company (PLN), independent power producers (IPP), and the Government of Indonesia. This paper asserts that consumers in Indonesia who do not have access to the grid will get benefits from the solar photovoltaic competitive costs. The consumers who have access to grid, however, will be indifferent in their position. In the longer term, these consumers will face the death spiral unless PLN, forced by the regulation, takes the loss. PLN will face bankruptcy due to the loss unless they invest in the distributed energy resources infrastructure. IPP will not gain in position due to unsupportive government regulations. Moreover, solar photovoltaic IPP will be vulnerable due to the policies that support imbalanced competition among renewable energies. On the other hand, the government will get some advantages that support their political agenda during the proliferation of solar photovoltaic.
\end{abstract}

\section{Introduction}

Solar energy has played a significant role in the last decade on the energy transition in many countries in the world. Solar photovoltaic (along with wind) has attracted massive amount in the global power sector investment over the last couple years [1-3]. The rise of solar photovoltaic (PV) technology in the electricity system has been gaining its momentum thanks to the significant falling cost $[2,3]$. Aligning with the Nationally Determined Contribution ${ }^{a}$ to achieve $31 \%$ of renewable energy share by 2050 , the Indonesian government aims to increase the solar PV generation capacity to $4 \mathrm{GW}$ in 2030 from $0.06 \mathrm{GW}$ in 2018 [4]. However, this target is considered too low by many scholars. Several studies explain that the potential of solar PV could be more than that. Liebman et al. ${ }^{[3]}$ argue that more than $35 \mathrm{GW}$ solar PV generation in total capacity can be achieved by 2027. IRENA $^{[5]}$ predicts that $47 \mathrm{GW}$ of installed capacity is potentially reached in Indonesia by 2030 . As solar ${ }^{b}$ resources in Indonesia are abundant and all year long [5, 6], it is common to see studies which examined how solar PV can technically emerge in the energy system.

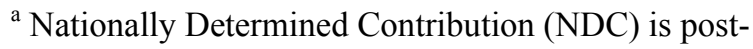
2020 climate actions as part of the Paris Agreement outlined by each country [30].

${ }^{\mathrm{b}}$ Wind is not included in this paper since the potential of wind is modest in Indonesia. In particular, if it is compared to the potential of solar energy [5]
}

However, less research is conducted to study how the emergence of solar PV might impact different stakeholders in the electricity market in Indonesia [1]. The increase of solar PV deployment will create winners and losers among the stakeholders in the electricity market [7]. The core stakeholders in the electricity market in Indonesia are defined as consumers, the national electricity company (PLN), the Central Government of Indonesia (the government) and independent power producers (IPP) [1, 6]. This paper will identify which major stakeholders will gain or lose from the emergence of solar PV in Indonesia. In order to assess this, it is crucial to examine how the electricity landscape will evolve, what benefits and drawback might potentially arise in each stakeholder view, and what regulations will be changing during the emerging transition of solar PV in the electricity sector.

\section{Discussion and Analysis}

\subsection{Electricity landscape in Indonesia}

Indonesia is the largest archipelago in the world, which comprises of 17000 islands. Most inhabitants live in the five big islands: Java, Sumatera, Sulawesi, Borneo, and Papua. Significant populations also live in the other 6000 small islands [6]. However, most electricity demand comes from Java, Bali, and Sumatra. $74 \%$ of the total of electricity produced in 2017 was sold in Java-Bali (as

\footnotetext{
Corresponding author: aqolbi@ieee.org
} 
one interconnected grid), $14 \%$ in Sumatra and the other from the rest of the islands [8]. Uneven distributions of populations, demand, and geographical structure make electricity services in Indonesia not uniformly reliable while the worst reliability is experienced by the eastern part of Indonesia [6]. The same report published that, in 2017 , only 60 million people have access to the main grid. The remaining 227 million have to rely on the isolated grid or do not have access to electricity. Diesel generators have been used widely for the past 30 years to supply electricity to the areas where on-grid access are not available due to its simple installation and lower cost $[6,9]$. The total capacity of on-grid diesel generators provided by the utility companies is $4.6 \mathrm{GW}$ in 2018 [4], whereas off-grid diesel generators which most villages used are accounted for around $1 \mathrm{GW}$ in total capacity [10].

\subsection{Off-grid and on-grid consumers}

Solar PV offers better benefits and reliable solutions for consumers in rural areas who do not have access to the grid [10-11]. These consumers will get an economic benefit from the emerging competitive cost of solar PV. The economic benefit is assessed based on the Levelized Cost of Electricity (LCOE). LCOE is a good starting point to compare benefits and competitiveness of different technologies $[10,12]$. Studies from Blum et al. $^{[10]}$ and Kunaifi et al. ${ }^{[6]}$ are good basis of LCOE data for off-grid technologies in Indonesia. Bias in the data is eliminated since it considers access to fuel, access to transmission lines, and the optimal usage of each plant [12]. The studies have demonstrated that a solar PV combined with diesel engine (hybrid) has relatively lower LCOE than a pure diesel generator-only. Figure 1 shows that most provinces have lower LCOE for Solar PV-hybrid compared to diesel generator alone. The further the consumers live from the city, the more they benefit from combining the diesel generator with solar PV since diesel generator LCOE depends so much on fuel cost. The fuel cost is much more expensive due to transportation cost when sold further from an urban area $[6,10]$. Currently, solar PV with battery is more economically viable compared to a diesel engine only in some provinces (see figure 2). Nevertheless, the capital cost of the battery, which is one of the most significant components in LCOE evaluation $[6,13,14]$, is predicted to be reduced to more than $60 \%$ by 2030 [15]. It will make solar PV with battery more appealing in the foreseeable future. Borenstein ${ }^{[12]}$ asserts that LCOE is only a start for economic comparison. Consumers who use solar PV will also get additional benefit from reduced externalities cost caused by greenhouse gas emissions from diesel and other fossil fuel generators [1, 12]. This is important for the consumers in Indonesia. Based on the interviews conducted by Kunaifi et al. ${ }^{[6]}$, the majority of the electricity consumers were concerned and worried about climate change. Thus, powering villages grid by solar PV will not only address the electricity access issue for the community but at the same time, address the issue of climate change mitigation in the rural areas.

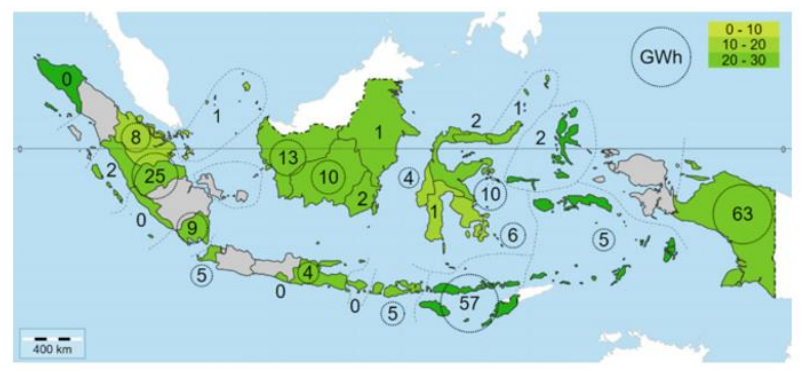

Fig. 1. ${ }^{[6]}$ Difference in LCOE of the hybrid PV/ diesel configuration versus diesel-only for each province in Indonesia. Positive differences indicate a lower LCOE for PV. The dashed circles show the toal amount of electrical energy delivered by PV. Grey provinces do not have rural households lacking grid access.

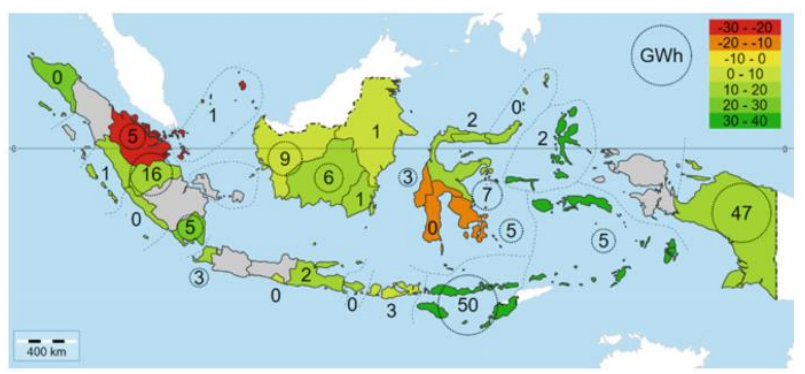

Fig. 2. ${ }^{[6]}$ Difference in LCOE of the stand-alone PV-battery systems versus diesel-only for each province in Indonesia. Positive differences indicate a lower LCOE for PV. The dashed circles show the total amount of electrical energy delivered by $\mathrm{PV}$, Grey provinces do not have rural households lacking grid access.

However, the impact of solar PV rising will be different to consumers who have access to PLN grid. A survey from Kunaifi et al. ${ }^{[6]}$ discovers that most consumers who have access to the PLN grid are willing to pay (WTP) $10 \%$ to $30 \%$ increase from the current electricity bill to get more reliable access of electricity. As we can see from figure 3, none of the technologies' LCOE, including solar PV hybrid and solar PV with battery, could achieve the WTP. All of the technologies' LCOE is more than the PLN retail price plus $30 \%$. Moreover, Veldhuis \& Reinders ${ }^{[16]}$ concludes that gridconnected PV LCOE is ranging between PLN retail price plus $50 \%$ and PLN retail price plus $200 \%$ in different provinces in Indonesia. Thus, going with solar PV soon is not a good economical option for these consumers. Furthermore, sometime in the future, when grid parity ${ }^{\mathrm{c}}$ is achieved, another phenomenon will happen. This phenomenon is explained in the analysis of gain and loss of PLN as the national electricity company on the next subsection.

\footnotetext{
${ }^{c}$ Grid parity is when the electricity cost of $\mathrm{PV}$ is equal to the cost of electricity from the grid [31].
} 


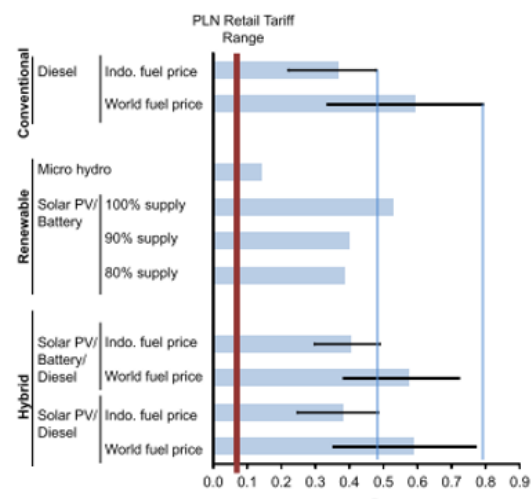

LCOE $\epsilon / \mathrm{kWh}$

Fig. 3. ${ }^{[10]}$ LCOE for generic Indonesian village grid with various technologies. The black lines represent the range of LCOE for any configuration with diesel components, demonstrating the influence of fuel costs due to remoteness of the village. The most left (smallest) LCOE within a variation represent locations close to distribution centre, the most right (highest) represent the furthest locations. The red vertical bars represent the PLN retail tariff range.

\subsection{PLN as the sole purchasing agency}

As Newbury ${ }^{[17]}$ stated in his paper, the distributed generation $^{\mathrm{d}}$, like solar PV and battery storage will likely trigger the destruction of monopoly and disrupt the incumbent business model. Indonesia electricity business adopts a single buyer model $[6,18]$. In this model, PLN is the sole purchasing agency of electricity produced by generation companies through a power purchase agreement (PPA). PLN coordinates the transmission, distribution, and retail. Setyawan ${ }^{[18]}$ infers that this model is hardly changed due to the restriction by the Indonesian constitution. An example in 2002 showed that an electricity law which allowed further competition of IPP in retailing was annulled by the Indonesian Supreme Court [18]. Based on the latest regulation, IPP can still sell electricity directly to consumers under a concession area permitted by the ministry of energy and mineral resources (MEMR). However, the first right of selling to consumers always goes to PLN [19]. The price for the IPP consumers shall be agreed by the MEMR. On the other hand, the electricity price sold by PLN to end consumers is determined by the government (MEMR or governor) subject to approval by the house representatives [20]. With the business model mentioned above, PLN bears most of the demand risks [21]. When the consumers disconnect completely from the grid due to grid parity, the total number of PLN consumers will drop. In the case of a liberalised market, this will create the death spiral ${ }^{\mathrm{e}}$. However, the impact in a single buyer

\footnotetext{
${ }^{\mathrm{d}}$ Distributed generation is locating power on the consumers site [32].

${ }^{\mathrm{e}}$ Death spiral is a condition when more consumers

disconnect completely from the grid, the higher

electricity price will be borne by the remaining

consumers since they have to pay for the fixed cost. This condition leads to even more consumers leaving the grid and so on [33].
}

market where PLN price is dictated by the government will be slightly different. If the government increases the electricity price to cover the PLN fixed cost, a similar story of the death spiral will happen. If the government does not increase the electricity price, then PLN will incur loss higher and higher. The latter scenario is more likely to happen. Since the Indonesian constitution 1945 amplifies that the use of vital utilities should be controlled by the state and use for the prosperity of its people, frequent tariff increase which backs PLN will be hardly achieved. The national electricity objective is energy security, universal access to electricity, and low price for electricity [1]. Thus, the increase of electricity price has always been politically tied [9] and it has been proven with some cases in Indonesia. Electricity price remained unchanged from $2004-2009$. On the year of 2004 until 2014, some efforts to increase the electricity price had been rejected by the Indonesian Parliament [9, 10]. In order to avoid bankruptcy when solar PV becomes economically viable, PLN as the incumbent major supplier needs to join the proliferation of solar PV technology by preparing the infrastructure which accommodates distributed energy resources (DER). Although the investment might not be profitable and tempted to hold the incumbent not to invest, which is called "incumbent curse", providing the innovative infrastructure earlier will ensure that PLN will not be left behind [17].

\subsection{IPP, regulations and the government position}

Involvement of the private sector like IPP in financing electricity access is important. However, government involvement is also essential to enable a favourable environment for the private business to participate [22]. In other words, IPP participation in the deployment of solar PV will heavily depend on government regulations [10]. Kunaifi et al ${ }^{[6]}$ have demonstrated how the up and down of solar PV installed capacity has a strong correlation with the government policy. From the year 2013 to 2016, the total solar PV installed capacity had increased significantly because the feed-in tariff was very attractive for IPP. The uniformly feed-in tariff of 25 cents USD $/ \mathrm{kWh}-30$ cents USD $/ \mathrm{kWh}$ was introduced across the country under the MEMR Regulation no.17/2013. However, in 2016 a new minister reduced the feed-in tariff which ranges from 14.5 cents $\mathrm{USD} / \mathrm{kWh}$ to 25 cents $\mathrm{USD} / \mathrm{kWH}$ depending on the provinces. This regulation depleted the solar PV installation. In 2017, solar PV installed capacity decreased significantly due to the approval of new regulation. The tariff for solar PV for IPP is capped at $85 \%$ below the regional production cost $\left(\mathrm{BPP}^{\mathrm{f}}\right)$ of PLN

\footnotetext{
${ }^{\mathrm{f}} \mathrm{BPP}$ reflects the PLN cost for generating power and procuring electricity supply from third-party suppliers such as IPP. However, the cost does not include cost of transmission. BPP is stipulated annually by the MEMR, based on a recommendation from PLN. BPP includes both national and local BPPs [34].
} 
which ranges from 7 cents USD/ $\mathrm{kWh}$ to 17 cents $\mathrm{USD} / \mathrm{kWh}[1,6]$. The modality of the project in this 2017 regulation is under build-own-operate and transfer (BOOT) scheme. The scheme is not attractive for investors since it prohibits IPP from having the project as the collateral asset. These regulations are seen as a high barrier for renewable energy projects such as solar PV [23]. As we can see from the examples above, it is essential to identify how feed-in tariff and other regulations will evolve since it heavily influences the investment environment and the risk/return profile of solar PV in Indonesia significantly [24].

The 2020 regulation which was released just for months ago brought some fresh air for renewable energy developers. BOOT scheme was revoked and replaced by the build-own-operate (BOO) scheme. The latest regulation also set feed-in tariff for hydro, geothermal, and waste power plant to be remained at maximum $100 \%$ capped from BPP. While the $85 \%$ capped for solar $\mathrm{PV}$ is remained [25]. It brings interesting relation between different renewable energy sources. First, it implies that PLN prioritises geothermal, hydro, and waste energy in their electricity share. Second, the enactment of BOO scheme will help capital incentive renewable energy project (such as geothermal) induces its competitiveness to other renewable energies [26]. Thus, the new regulation puts solar PV position in jeopardy among other renewable energy sources.

Setting a feed-in tariff which satisfied both the monopoly company and IPP in a single buyer market model is not easy. Governments have been always struggling set the fair amount for both parties [1]. As previously discussed, the lack of change of the singlebuyer market model means that the feed-in tariff policy will remain unattractive for solar PV IPP. The new regulation on 2020 did not address the main concern of IPP on the feed-in tariff [25]. In the past, MEMR has tried to do another mechanism other than feed-in tariff. They allowed the auction mechanism for less than 10 MW renewable energy project. However, this mechanism was revoked by the Indonesian Supreme Court in 2015 with the argument that refers to the Indonesian Constitution 1945 about the vital goods ([5]). With the $85 \%$ capped policy, every additional solar PV to the systems will reduce the BPP for the following year. In the future, when the decreasing rate of LCOE can not keep up with the reduction rate of BPP, solar PV deployment by IPP will be slowing down [1]. If the government tried to increase the feed-in tariff, based on the regulation, the government needs to fund the gap between the tariff to the BPP of PLN [5]. The government will be loaded with extensive budgeting to support this rapid transition of solar PV. IRENA ${ }^{[5]}$ argues that the investment needed to accelerate solar PV to deployment to achieve $47 \mathrm{GW}$ in 2030 is USD 6.6 billion. Current international funding to support the renewable energy transition in Indonesia is very small [1]. It will put the government in a poor position. It is unlikely that the government will take this option. The government objective in electricity in Indonesia is to provide energy to support economic growth and prosperity to the people while maintaining low electricity price [1]. Renewable energy is only a tool to achieve that. Investing in renewable energy while the coal next door is more economically viable will politically not be acceptable [1]. Thus, government regulation in feed-in tariff will hardly incentivise IPP.

The latest event of COVID-19 has triggered the government to review renewable energy regulations. The government has realised that although the demand for electricity in Indonesia dropped during COVID-19, the demand from variable renewable energy like solar globally is not affected [27]. A strategy that the government just released to support solar PV in response to COVID-19 is allowing floating PV to be installed on reservoirs and dam area. This regulation, which is under the Ministry of Public Works no 6. 2020, allowed floating PV to occupy a maximum of $5 \%$ reservoirs or dam area. However, the effect of adding this regulation will not be significant. The government predicts that 612 MW floating PV will be added by 2025 . Nevertheless, the target of solar PV installed in 2025 is still kept at 4 $\mathrm{GW}$, exactly the same as what the government declared in the Indonesia National Energy Plan 2019 [27]. In short, IPP will not gain in position for the proliferation of solar PV in Indonesia due to the ineffective government regulation.

Although government regulation to support the emergence of solar PV is questionable, the emergence of solar PV deployment will bring benefit to the government. The government, which aimed $100 \%$ electrification ratio in 2025 , will be helped by the deployment of solar PV in rural areas in Indonesia [28]. Lower electrification ratio is common in rural areas due to geographical challenges and economic challenges to connect the consumers to the grid [6]. This paper has demonstrated how solar PV becomes a viable solution to electrify rural areas in Indonesia. In addition, higher installation of solar PV in the electricity generation will also help the government to achieve the greenhouse gas (GHG) emissions reduction target from the energy sector by 2030 [29]. Currently, the electricity sector contributes to more than $50 \%$ of the total emission in the energy sector. Electricity generation has produced more than 231 Mt CO2e a year [29]. With the help of solar PV beating diesel generator economically, lower GHG emissions will be produced caused by the less usage of diesel generators. The solar PV proliferation will help the Indonesian government to achieve some of its political agenda such as the emission reduction target, and the increase of electrification ratio.

\section{Result and Conclusion}

In summary, this paper has investigated which stakeholders will win and lose related to the emergence of solar PV technology in Indonesia. It argues that the consumers who do not have access to the grid will get benefits from the reduction of electricity cost and the reduction of GHG emissions caused by less usage of diesel generators. In the shorter term, the consumers who have access to PLN grid will be indifferent in their position. However, in the longer term, they will face the 
death spiral unless PLN, forced by the regulation, takes the loss. PLN will be in a bad position in the scenario where they have to take the loss. They will face bankruptcy due to the loss unless they invest in the distributed energy resources infrastructure. Furthermore, IPP will not gain in position because the government will not issue any policies that will put them in an unfortunate place to support the rapid deployment of solar PV. Besides, solar PV IPP will be vulnerable due to the government regulations that support imbalanced competition among renewable energies. On the other hand, the government will get some advantages that make them achieve some of their political agenda during the proliferation of solar PV.

The author acknowledges the Indonesia Endowment Fund for Education that has supported and funded this research and Mark Grenning for his guidance on the paper.

\section{References}

1. R. Bridle, P. Gass, A. Halimajaya, L. Lontoh, N.McCulloch, E. Petrofsky, and L. Sanchez, "Missing the 23 Per Cent Target: Roadblocks to the development of renewable energy in Indonesia," (2018)

2. IEA, "World Energy Investment 2019 Edition," (2019)

3. A. Liebman, W. Foster, M. Pujantoro, P. Gordon, F. Tumiwa, J. Giwangkara, and A. Tampubolon, "A Roadmap for Indonesia' s Power Sector: How Renewable Energy Can Power Java-Bali and Sumatra," (2019)

4. MEMR, "Rencana Umum Ketenagalistrikan Nasional 2019-2038," (2019)

5. IRENA, "Renewable Energy Prospects: Indonesia, a REmap analysis," Abu Dhabi, (2017)

6. K. Kunaifi, A. Veldhuis, and A. Reinders, The Electricity Grid in Indonesia: The Experiences of End-users and Their Attitudes Toward Solar Photovoltaics. (2020)

7. N. Kelsey and J. Meckling, "Who wins in renewable energy? Evidence from Europe and the United States," Energy Res. Soc. Sci., vol. 37, no. August (2017), pp. 65-73, 2018, doi: 10.1016/j.erss.2017.08.003.

8. National Energy Council, "Rencana Umum Energi Nasional," Ruen. Dewan Energi Nasional, (2017)

9. P. J. Burke and S. Kurniawati, "Electricity subsidy reform in Indonesia: Demand-side effects on electricity use," Energy Policy, vol. 116, no. March, pp. 410-421, (2018), doi: 10.1016/j.enpol.2018.02.018.

10. N. U. Blum, R. Sryantoro Wakeling, and T. S. Schmidt, "Rural electrification through village grids - Assessing the cost competitiveness of isolated renewable energy technologies in Indonesia," Renew. Sustain. Energy Rev., vol. 22, pp. 482-496, (2013), doi: 10.1016/j.rser.2013.01.049.
11. D. P. Kaundinya, P. Balachandra, and N. H. Ravindranath, "Grid-connected versus stand-alone energy systems for decentralized power-A review of literature," Renew. Sustain. Energy Rev., vol. 13, no. 8, pp. 2041-2050, (2009), doi: 10.1016/j.rser.2009.02.002.

12. S. Borenstein, "The private and public economics of renewable electricity generation," J. Econ. Perspect., vol. 26, no. 1, pp. 67-92, (2012), doi: 10.1257/jep.26.1.67.

13. A. S. Mundada, K. K. Shah, and J. M. Pearce, "Levelized cost of electricity for solar photovoltaic, battery and cogen hybrid systems," Renew. Sustain. Energy Rev., vol. 57, pp. 692-703, (2016), doi: 10.1016/j.rser.2015.12.084.

14. T. T. D. Tran and A. D. Smith, "Incorporating performance-based global sensitivity and uncertainty analysis into LCOE calculations for emerging renewable energy technologies," Appl. Energy, vol. 216, pp. 157-171, (2018), doi: 10.1016/j.apenergy.2018.02.024.

15. IRENA, Electricity storage and renewables: Costs and markets to 2030, (2017).

16. A. J. Veldhuis and A. H. M. E. Reinders, "Reviewing the potential and cost-effectiveness of grid-connected solar PV in Indonesia on a provincial level," Renew. Sustain. Energy Rev., vol. 27, pp. 315-324, (2013), doi: 10.1016/j.rser.2013.06.010.

17. P. Newbury, "Creative Destruction and the Natural Monopoly 'Death Spiral': Can Electricity Distribution Utilities Survive the Incumbent's Curse?," SSRN Electron. J., (2013), doi: 10.2139/ssrn.2479085.

18. D. Setyawan, "Assessing the current indonesia's electricity market arrangements and the opportunities to reform," Int. J. Renew. Energy Dev., vol. 3, no. 1, pp. 55-64, (2014), doi: 10.14710/ijred.3.1.55-64.

19. Akset Law, "Renewable Energy in Indonesia," (2019). [Online]. Available: https://www.lexology.com/library/detail.aspx?g=0cc 817b9-55a5-4258-a2f5-4b1669721c5b. [Accessed: 28-May-2020].

20. Akset Law, "Regulation of Electricity Utilities Sales of Power," (2018). [Online]. Available: https://www.lexology.com/library/detail.aspx?g=5b 528d6b-f5b4-4bc2-bc74-777596fd8c8f. [Accessed: 28-May-2020].

21. PWC, "Refresher on Interpretation of Financial Accounting Standards No. 16 (Service Concession Arrangements)," (2017).

22. S. C. Bhattacharyya, "Financing energy access and off-grid electrification: A review of status, options and challenges," Renew. Sustain. Energy Rev., vol. 20, pp. 462-472, (2013), doi: 10.1016/j.rser.2012.12.008.

23. IESR, "Indonesia Clean Energy Outlook: Tracking Progress and Review of Clean Energy Development in Indonesia.," Jakarta, (2019). 
24. T. S. Schmidt, N. U. Blum, and R. Sryantoro Wakeling, "Attracting private investments into rural electrification - A case study on renewable energy based village grids in Indonesia," Energy Sustain. Dev., vol. 17, no. 6, pp. 581-595, (2013), doi: 10.1016/j.esd.2013.10.001.

25. Assegaf Hamzah \& Partners, "Client Update : High Hopes for Indonesia' s Renewable Energy-Based Electricity," (2020). [Online]. Available: https://www.ahp.id/client-update-28-april-2020.

26. A. S. Wahjosoedibjo and M. Hasan, "Indonesia's Geothermal Development: Where is it Going?," in 43rd Workshop on Geothermal Reservoir Engineering, (2018), doi: 10.4028/www.scientific.net/AMM.268-270.1594.

27. MEMR, "Kebijakan Pemerintah Dalam Peningkatan Peran Energi Terbarukan Paska Covid-19," (2020).

28. PWC, "Power in Indonesia: Investment and Taxation Guide November 2018 6th Edition," (2018).

29. Republic of Indonesia, Indonesia Second Biennial Update Report: Under the United Nations Framework Convention on Climate Change, vol. 3, no. 2. (2018).

30. UNFCC, "Nationally Determined Contributions (NDCs)," (2020). [Online]. Available: https://unfccc.int/process-and-meetings/the-parisagreement/the-paris-agreement/nationallydetermined-contributions-ndes.
31. P. Denholm, R. M. Margolis, S. Ong, and B. Roberts, "Break-Even Cost for Residential Photovoltaics in the United States : Key Drivers and Sensitivities Break-Even Cost for Residential Photovoltaics in the United States : Key Drivers and Sensitivities," Tech. Rep. NREL/TP-6A2-46909, no. December, p. 33, (2009).

32. T. Ackermann, G. Andersson, and L. Söder, "Distributed generation: A definition," Electr. Power Syst. Res., vol. 57, no. 3, pp. 195-204, (2001), doi: 10.1016/S0378-7796(01)00101-8.

33. Energy Networks Australia, "The Death Spiral," (2020). [Online]. Available: https://www.energynetworks.com.au/news/energyinsider/the-death-spiral/.

34. SSEK Indonesian Legal Consultants, "Indonesia Introduces New Tariff Regime for Renewable Energies," Association of Corporate Counsel Australia, (2018). [Online]. Available: https:/www.lexology.com/library/detail.aspx?g=a15 bd966-4144-477a-954a-a12d58ff3b6a. [Accessed: 28-May-2020]. 